\title{
Imagem Pública da Enfermeira Brasileira: Curso de Enfermeiras da Assistência Particular Nossa Senhora da Gloria (1920-1928)
}

\author{
Brazilian Public Image of the Nurse: \\ Course of Nurse's Assistência Particular Nossa Senhora da Gloria
} (1920-1928)

\section{Imagen Pública de la Enfermera Brasileña: \\ Curso de Enfermería de Atención Privada Nuestra Señora de la Gloria (1920-1928)}

Fernando Porto ${ }^{1}$, Elaine Fonseca ${ }^{2}$, Anna Karine de Mattos Desvelandes ${ }^{3}$, Luciane Luchesi Barizon ${ }^{4}$ Wellington de Mendonça Amorim ${ }^{5}$

${ }^{1}$ Pós-doutor em Enfermagem pela Escola de Enfermagem da Universidade de São Paulo. Professor da Escola de Enfermagem Alfredo Pinto, da Universidade Federal do Estado do Rio de Janeiro. Membro do grupo de pesquisa LAPHE, LACENF e LASENF. Vice-presidente da Academia Brasileira de História da Enfermagem.

${ }^{2,3}$ Enfermeira. Mestranda do Programa de Pós-Graduação Mestrado em Enfermagem da Universidade Federal do Estado do Rio de Janeiro, da Escola de Enfermagem Alfredo Pinto. Membro do grupo de pesquisa LAPHE e LACENF.

${ }^{4}$ Doutora em Enfermagem pela Escola de Enfermagem de Ribeirão Preto, da Universidade de São Paulo (USP). Professora da Escola de Enfermagem de Ribeirão Preto USP. Membro do grupo de pesquisa LAPHE, LACENF e LASENF. Diretoria Academia Brasileira de História da Enfermagem

${ }^{5}$ Doutor em Enfermagem pela Escola de Enfermagem Anna Nery, da Universidade Federal do Rio de Janeiro. Professor da Escola de Enfermagem Alfredo Pinto, da Universidade Federal do Estado do Rio de Janeiro. Membro do grupo de pesquisa LAPHE, LACENF e LASENF.

Cómo citar este artículo en edición digital: Porto, F; Fonseca, E; de Mattos Desvelandes, A.K; Luchesi Barizon, L; de Mendoça Amorim, W. (2012) Imagem Pública da Enfermeira Brasileira: Curso de Enfermeiras da Assistência Particular Nossa Senhora da Gloria (1920-1928). Cultura de los Cuidados. (Edición digital) 16, 32. Disponible en: http://dx.doi.org/10.7184/cuid.2012.32.06 Correspondencia: Fernando Porto.E-mail: ramosporto@openlink.com.br Recibido: 20/11/2011 - Aceptado: 25/02/2012

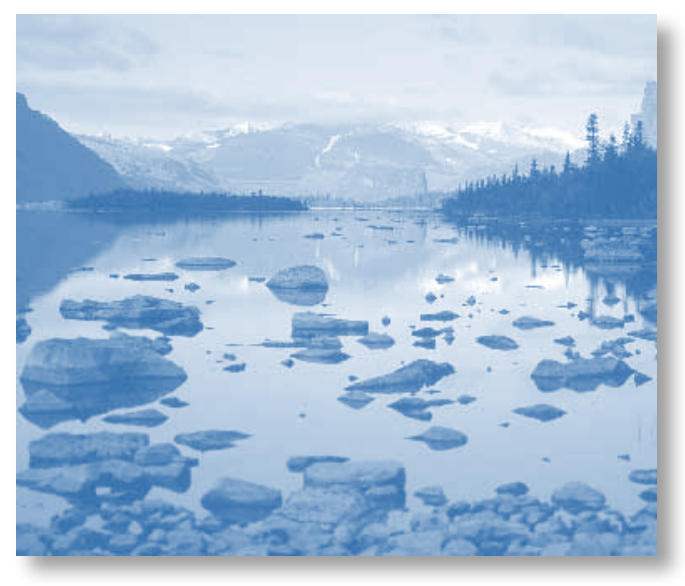

ABSTRACT

Study with a central focus of analysis in fac- simile posted on the magazine Fon-Fon on the Course of Nursing of Assistencia Nossa Senhora da Gloria. Analysis approach was through the perspective of historical-semiotic. Methodologically, the documents were written and imagery used, the latter being analyzed through a matrix analysis, and historically contextualized. The results showed a further course of Nurses before, probably unknown to researchers in the History of Nursing in Brazil, which increasingly must relativize the studies on this topic since the documentation of collections and many governments must be scrutinized to hit assertive.

Keywords: Nursing, Nursing History and Image. 


\section{RESUMEN}

Estudio con un enfoque central de análisis en fac-símile publicado en la revista Fon-Fon en el Curso de La Enfermerías da Assistencia Nossa Senhora da Gloria. El análisis se enfoque desde la perspectiva histórico-semiótica. Metodológicamente, los documentos fueron escritos y las imágenes, este último se analiza a través de una matriz de análisis, y contextualizado histórico. Los resultados mostraron más un curso de Enfermeras antes, probablemente desconocido para los investigadores de la Historia de la Enfermería en Brasil, que cada vez debe relativizar los estudios sobre este tema desde la documentación de las colecciones y muchos gobiernos deben ser examinadas para golpear asertivo .

Palabras clave: Enfermería, Historia de la Enfermería y de la imagen.

\section{RESUMO}

Estudo com foco central de análise no facsímile veiculado na Revista Fon-Fon sobre o Curso de Enfermeiras da Assistência Nossa Senhora da Glória. Abordagem de analise ocorreu mediante a perspectiva da histórica-semiótica. Metodologicamente, os documentos utilizados foram escritos e imagético, sendo este último analisado, por meio de uma matriz de análise, e contextualizado historicamente. Os resultados apontaram mais um Curso de Enfermeiras antes, provavelmente, desconhecidos dos pesquisadores em História da Enfermagem no Brasil, o que cada vez mais se devem relativizar os estudos na presente temática, pois a documentação dos acervos precisam, e muito, serem perscrutados para certas assertivas.

Palavras-chave: Enfermagem, História da Enfermagem e Imagem.

\section{INTRODUÇÃO}

$\mathrm{Na}$ publicação da Revista Cultura de los Cuidados referente ao primeiro semestre de 2010, número 27, foi veiculado o artigo "Escolas e Cursos de Enfermagem na História da Profissão no Brasil (1890-1922)" de autoria de Fernando Porto e Wellington de Mendonça Amorim, que em meio ao texto, os autores relataram que Cursos e Escolas de Enfermeiras no eixo Rio - São Paulo, no Brasil, foi criado, considerando que alguns se desconhecem a sua materialização no período proposto, dentre eles, o Curso de Enfermeiras da Assistência Particular Nossa Senhora da Gloria, no Rio de Janeiro.

Mediante investimento em buscas documentais sobre a Instituição foi possível localizar registros escritos na Revista Brazil-Medico e no documentário intitulado Assistência Pública e provada no Rio de Janeiro: história e estatística. Além destes, um fac-símile com a imagem das alunas e a professora do Curso de Enfermeiras da Assistência Particular Nossa Senhora da Glória, no Rio de Janeiro veiculado na Revista Fon-Fon.

Neste sentido, tem-se como objeto de análise a representação visual do Curso de Enfermeiras da Assistência Particular Nossa Senhora da Gloria, com objetivo descrever, analiticamente, o fac-símile, veiculado na Revista Fon-Fon, sobre o início das aulas do Curso de Enfermeiras da Assistência Particular Nossa Senhora da Gloria, no Rio de Janeiro, na perspectiva semiótica da construção do mecanismo da imagem pública da Enfermeira brasileira.

A relevância do estudo é a tentativa de preencher mais uma das lacunas da História da Enfermagem Brasileira, apesar dos diversos estudos produzidos, em especial no período nas décadas de 1910 e 1920, pelos pesquisadores brasileiros, pois ao se perscrutar novos 
documentos, também, novos dados emergem no sentido de proporcionar outras versões e interpretações para a História da Enfermagem Brasileira.

Ademais, é uma das propostas do Laboratório de Abordagens Cientificas da História da Enfermagem (LACENF) vinculado ao Laboratório de Pesquisa de História da Enfermagem (LAPHE), da Escola de Enfermagem Alfredo Pinto (EEAP), da Universidade Federal do Estado do Rio de Janeiro (UNIRIO) avançar em propostas metodológicas, em especial da imagem, e (des)cristalizar aspectos da trajetória profissional da enfermagem brasileira.

\section{MÉTODO}

O documento imagético utilizado para análise é um fac-símile, considerado como reprodução da imagem, por entender que o mundo da imagem possui dois domínios material (como representações visuais - desenhos, pinturas, gravuras, fotografias e as imagens cinematográficas, televisivas, holográfica e infográficas) e imaterial (imagens de nossa mente - visões, fantasias e imaginações), considerando que uma depende da outra (Santeaella e Noth, 1999; Fonseca e Porto, 2010).

Para a realização da interpretação analítica do fac-símile foi utilizado uma matriz de análise testada na tese de doutoramento de Fernando Porto (2007) adaptada dos estudos das pesquisadoras Ana Maria Maud-Andrade (1997), Tânia Cristina Franco Santos (1999) e Maria Ciavata (2002) e que no momento se encontra em aplicação no projeto matriz intitulado "A imagem pública da enfermeira brasileira”

Esta matriz de análise foi elaborada com base em dois conceitos da semiótica: plano de expressão e conteúdo. $\mathrm{O}$ plano de expressão se refere à manifestação desse conteúdo como um sistema de significação verbal, não-verbal ou sincrético e o plano de conteúdo ao signi- ficado do texto. Em outras palavras, o que o texto relata e como ele faz para dizer o que diz - a mensagem (Pietroforte, 2004).

Cabe destacar, neste sentido, o que revela Ana Maria de Souza Mauad-Andrade, quando cita que, ao se analisar a mensagem imagética, como um fenômeno de produção de sentido, dois conceitos históricos são fundamentais: cultura e ideologia. Estes conceitos elucidam a mensagem concebida, sobre às escolhas realizadas de acordo com a dinâmica social à época, que deve ser articulada a caracterização de sua compreensão no contexto da abordagem. Nesta perspectiva, a abordagem semiótica conduz o estudo à luz da perspectiva histórica-semiótica (Mauand-Andrade, 1991).

A matriz é composta de quatro partes, a saber: dados de identificação, plano de expressão, plano de conteúdo e dados complementares obtidos em outras fotografias

Os dados de identificação se referem ao: local do acervo - nome da instituição pública ou do proprietário, quando particular; nome da revista ilustrada - como ela se denomina; ano de publicação; número do exemplar; página que se encontra a imagem fotográfica e data da publicação do exemplar da revista e título ou manchete que acompanha a fotografia.

Os dados para o plano de expressão são: crédito da imagem fotográfica - autoria da produção da imagem; relação texto imagem: fotorreportagem é um tipo de notícia constituída, exclusivamente, por fotos com legendas, sem qualquer bloco de texto de apoio ou contextualização, com imagens seqüenciadas ou não opostamente à fotojornalismo; legenda: se refere a um texto para identificar os retratados e/ou cena na foto jornalística ou ilustração, considerada, também, como texto-legenda, sendo de texto curto e sempre editado com foto; resumo do texto; tipo de foto: a foto posada e flagrante, conhecida também como ins- 
tantânea; formato: desenho geométrico; plano - os planos fotográficos são do tipo: plano geral - quando retrata ambientes amplos, geralmente, em exterior: plano conjunto - destinado às pessoas quando elas não são os objetos centrais da foto; plano americano - é o plano no qual as pessoas são retratadas da cintura para cima; primeiro plano - conhecido como close de pessoas ou objetos; e o plano detalhe - variante do primeiro em sua máxima representação; sentido: se refere à imagem em relação à página; localização da imagem na página: essas zonas de visualização são áreas estratégicas, tendo como princípio a visão, pois se fixam no lado superior à esquerda do papel, por estarmos condicionados pela escrita ocidental.

Esta tem início da esquerda para a direita, o que caracteriza o alicerce obrigatório dos olhos, influenciando decisivamente em nosso comportamento na leitura. A lógica racional para a leitura ocidental dá origem ao esquema em seis zonas de visualização. A zona primária ou principal (1) contém elementos de forte atração para chamar à atenção do leitor. Como a visão instintivamente se desloca com rapidez em diagonal para o lado inferior oposto (zona morta - 4), a rota básica da vista se projeta do lado superior esquerdo (zona morta - 3) para o lado inferior direito (zona secundária - 2). Neste sentido, a importância do centro ótico (5) e geométrico (6) da página necessita oferecer aspectos atrativos para que a leitura seja or-

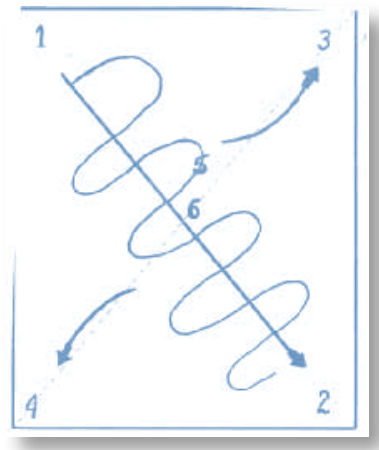
denada, com racionalidade, sem o deslocamento brutal da visão (Silva, 1985).

Figura n. 1 - Zonas de visualização (Silva, 1985, 45-48)
Os dados do plano de conteúdo são: local retratado: natural, cenário montado, interno, externo e o espaço geográfico; pessoas retratadas: grupo misto, grupo masculino, grupo feminino, grupo infantil, quantas pessoas retratadas; tema da imagem retratada; atributos pessoais: vestimentas e acessórias que as pessoas ostentam; atributos de paisagem: objetos, característica do cenário retratado, elementos presentes para composição da cena.

Os dados complementares obtidos de outra imagem fotográfica são: origem da informação: localização da informação e Informação complementar- articulações possíveis com a imagem analisada.

Ressalta-se que é de interesse para a leitura do texto imagético, a utilização de ampliação da imagem, por meio dos recursos da informática na tela do microcomputador no comando pelo zoom ou, então, pela projeção em multimídia, pois capta melhor o conteúdo do material a ser analisado. Esta ampliação da imagem é também sugestão da pesquisadora Miriam Moreira Leite (1993), que comunga da utilização deste recurso, mas adverte sobre a possibilidade de distorção da imagem original.

Mediante o exposto a matriz foi aplicada ao fac-símile de forma sistematizada e ao final apresentada uma síntese interpretativa, como as considerações finais do estudo em apreço.

\section{RESULTADOS}

\section{Contexto histórico sócio-político e da enfer- magem}

No Brasil, em especial no Rio de Janeiro, as duas primeiras décadas do século XX soaram com o tom enunciativo de modernização, pois após a abolição, se deu início uma nova fase da expansão da cidadania brasileira, se desdobrando, ainda, com o fim da Monarquia, a qual possibilitou ampliação da autoridade pública (Viscardini, 2009). 
Para tanto, a modernização implicou em mecanismos sociais de racionalização da vida sócio-sanitário que se materializou em ações de higiene, como suporte ideológico, como opressão à população carente. Esta opressão buscava afastar dos centros urbanos do Rio de Janeiro, aspectos que se considerava obstáculo para o processo de modernização (Rangel, 2010).

Cabe ressaltar que, o entendimento de população carente era entendido como pobreza no sentido de ausência de renda e riqueza; de educação e saúde e; a presença da exclusão étnica ou de gênero. Este impedia que os indivíduos participassem de forma ativa na política e cultural da sociedade à época (Viscardi, 2009).

A solução higienista se relacionava com as propostas de cunho assistencialista ou filantrópico. Esta se configurava sob o estatuto da tutela aos pobres impossibilitados de se transformarem em força de trabalho assalariado, não lhes restando alternativa senão a filantropia (Rangel, 2010).

Em 1908, a Prefeitura do Distrito Federal, o Rio de Janeiro, na gestão do médico Francisco Marcelino de Souza Aguiar (1906-1909), se promoveu o Congresso Nacional de Assistência Pública e Privada, durante a realização do centenário de abertura dos portos. Esse evento foi divido em quatro sessões: Assistência médica; Assistência pública em geral; Assistência à infância e Assistência externa (Sanglard, 2008).

As conclusões do evento foram, em síntese, que no que tangia à assistência de urgência e à hospitalar seria de competência do poder municipal, que as cidades com população numerosa ou industrializada deveriam ter um serviço de urgência e que o Posto Central da Assistência do Rio de Janeiro fosse considerado como modelo a ser aplicado em outras cidades. Ademais, sobre a assistência hospitalar os congressistas entenderam a necessidade a urgência da construção de um hospital sobre aos auspicio do município do Rio de Janeiro, considerando ampliação do Asilo São Francisco de Assis e a criação de um hospital-asilo para incuráveis com capacidade de duzentos leitos. Este último se tornou meta para os políticos no sentido de incentivarem a construção de hospitais públicos no Distrito Federal, que se mostrou ineficiente mediante a epidemia da gripe espanhola (Sanglard, 2008).

Entre 1917 a 1918 foi marcado, principalmente, por dois fatores que influenciaram e redirecionaram os debates acerca da assistência de modo geral, a saber: hospitalar - pela eclosão das graves operarias no eixo Rio- São Paulo, que conduziu à Câmara dos Deputados a discussão sobre o trabalho feminino e infantil; os acidentes de trabalho e a proteção social e; a gripe espanhola, a qual chamou a atenção para o problema crônico dos grandes centros urbanos pela deficiência dos centros de socorro à população carente (Sanglard, 2008).

No ano de 1920, a proposta defendida pelo médico gaúcho Domingos Mascarenhas, na Câmara dos Deputados, parecida com a do sanitarista Carlos Chagas, no sentido que o Hospital da Santa Casa de Misericórdia não tinha mais condições de se expandir e atender às necessidades da assistência pública. Mascarenhas conseguiu transformar em decreto o projeto para a construção de hospitais no Distrito Federal, seguindo o modelo arquitetônico germânico. Este projeto viria a garantir a gratuidade aos indigentes, os outros pagariam o proporcional as suas condições financeiras, mas em virtude da aproximação com as festividades do centenário da Independência do Brasil careceu de ser implantado, considerando, ainda, que o mesmo foi reeditado por mais duas vezes, mas sem sucesso, mesmo diante do acirramento das criticas (Sanglard, 2008).

Ressalta-se que no início dos anos de 1920 se teve a criação do Departamento Nacional 
de Saúde Pública, que desencadeou a Reforma Sanitária, liderada por Carlos Chagas. A Reforma Sanitária se deu diante da repercussão da falência dos serviços de saúde publica em face da epidemia da gripe espanhola no pós-guerra. Esta reforma era circunscrita por dois discursos ideológicos - tecnicista e o higienista. O primeiro valorizava a racionalidade técnica e cientifica e o segundo buscava o prestígio científico e tentava evitar o debate político (Porto e Santos, 2008).

Nas festividades do centenário da Independência do Brasil, dois eventos se destacaram no âmbito da assistência pública no Rio de Janeiro: a publicação da obra intitulada "Assistência Pública e Privada no Rio de Janeiro: historia e estatística" e o Congresso Nacional dos Práticos (Sanglard, 2008).

A elaboração da obra supracitada surgiu na gestão do prefeito Bento Ribeiro (19101914) - o advogado, escritor e jornalista - que incumbiu a Ataulfo de Paiva o levantamento estatístico dos estabelecimentos de assistência pública e privada, no Distrito Federal. Este levantamento buscou diagnosticar o combate à crescente pobreza que havia no Rio de Janeiro, incluindo as associações mutualistas, entendidas como àqueles cujos trabalhadores garantiam por meio de renda complementar, o acesso ao atendimento médico ou diminuir os efeitos da exclusão social, na medida em que as sociedades ofereciam espaço para o exercício da cidadania e da política, (Viscardi, 2009).

Para esse fim, Ataulfo de Paiva organizou três tipos diferentes de questionários, que foram enviados às associações de auxílio mútuo, aos asilos e recolhimentos, e aos hospitais. Além disso, visitou as instituições no que se refere a obtenção informações pormenores. Foi recenseado o total de seiscentos e vinte e quatro Estabelecimentos de Saúde, que se encontravam em funcionamento nos anos de 1912 a
1920, no Rio de Janeiro (Viscardi, 2009).

Dentre os Estabelecimentos de Saúde recenseados, se delimitou a Assistência Particular Nossa Senhora da Glória, no Rio de Janeiro. Este funcionou um curso para a formação de Enfermeiras, com imagem veiculada na Revista Fon-Fon, em 1928.

Á época, a Enfermagem no Distrito Federal tinha, pelo que aponta os estudos realizados pelos pesquisadores Almerinda Moreira (1995), Jussara Sauthier e Ieda Barreira de Alencar (1999), Maria Lucia Mott e Maria Alice Tsunechiro (2002), Maria Lucia Mott e Taka Oguisso (2003), Fernando Porto e Tania Cristina Franco Santos (2008), a saber: Escola Profissional de Enfermeiros e Enfermeiros (1890), Escola Prática da Cruz Vermelha Brasileira Órgão Central (1916), Curso de Enfermeiras da Policlínica de Botafogo (1917) e a Escola de Enfermeiras do Departamento Nacional de Saúde Pública (1922).

A Escola Profissional de Enfermeiros e Enfermeiras, atual Escola de Enfermagem Alfredo Pinto, da Universidade Federal do Estado do Rio de Janeiro (UNIRIO), foi criada dez meses depois da proclamação da República no país, quando se deu a separação do Estado com a Igreja. Anos mais tarde (1921) foi desdobrada em três seções - Masculina, Mixta e Feminina - a feminina foi denominada Escola Profissional de Enfermeiras Alfredo Pinto, que funcionou na Colônia de Alienadas do Engenho de Dentro e a Mixta no Hospício Nacional de Alienados.

O Curso de Enfermeira Voluntária criado no contexto inicial da I Guerra Mundial (1914), que por interesse das Damas da Cruz Vermelha Brasileira propuseram e foi apoiada pela Diretoria da Instituição à época a criação do Curso de Enfermeira Profissional (1916), mediante a inserção do Brasil no conflito, quando a Cruz Vermelha Brasileira - Órgão 
Central - também criou a Escola Prática de Enfermeiras, abrigando ambos os Cursos.

A Policlínica de Botafogo criou em 1917 o Curso de Enfermeiras da Policlínica de Botafogo, com a justificativa de preparar Enfermeiras, caso fosse necessário o encaminhamento de profissionais para o atendimento bélico, bem como para atender a demanda interna da instituição, que formou duas turmas no período de 1917-1920.

Escola de Enfermeiras do Departamento Nacional de Saúde, atual Escola de Enfermagem Anna Nery, da Universidade Federal do Rio de Janeiro, foi criada no contexto da Reforma Sanitária, liderada por Carlos Chagas, e subvencionada apela Fundação Rockefeller em 1922.

Essas eram as Escola e Cursos que os pesquisadores evidenciaram em suas pesquisas, delimitado no Rio de Janeiro, com funcionamento regular e que contribuíram para o desenvolvimento da Enfermagem no Brasil.

\section{Assistência Particular Nossa Senhora da Gloria}

A Assistência Particular Nossa Senhora da Gloria pelo documento intitulado Assistência Pública e Provada no Rio de Janeiro - História e Estatística (1922, 643 e 644) foi fundada em 1 de maio de 1919, situada na rua Tucuman número um, bairro do Flamengo,no Rio de Janeiro, por Tereza Alves e Antonio Marzullo, com fins de prestar socorros médicos, dentários, de parteira e toda a espécie de assistência em geral aos necessitados.

A manutenção das despesas financeiras da Instituição era custeada pelos sócios em categorias, a saber: iniciadores, fundadores, contribuintes, benfeitores e presidentes honorários. Os sócios para serem admitidos eram obrigados a pagarem o valor da jóia de $10 \$ 000$ e para gozarem dos direitos da hospitalizações o valor de $20 \$ 000$ de uma só vez ou $250 \$$ de 20 \$o mês.

A Instituição mantinha fundo de reserva denominado de "Mialheiro", sendo este de $2 \%$ da renda bruta e $25 \%$ sobre os donativos em dinheiro. Esta verba era para socorrer os sócios enfermos e inválidos, por meio de pensões e outros auxílios necessários de acordo com o estado de cada um, bem como às grávidas e o recolhimento de proteção à infância desprotegida.

O Regulamento Institucional composto de dez artigos, destaca-se em especial atenção ás mulheres grávidas e as crianças desprotegidas e nascidas na Instituição.

Pouco se sabe deste Estabelecimento de Saúde, mas pode-se evidenciar no regulamento a preocupação com as mulheres grávidas e a proteção à infância. Neste sentido, também foi possível se identificar que o corpo administrativo era composto de sete mulheres e cinco homens, o que pode ratificar as preocupações com o gênero feminino.

Essa preocupação pode ter sido fator também desencadeante para a formação de Enfermeiras na Instituição anos mais tarde (1928), ou até mesmo anos antes anterior, o que não se pode afirmar no momento, mesmo considerando que o Curso se encontrava previsto no Estatuto publicado em 1920 em Diário Oficial da União (Revista Brazil-Medico 1920).

\section{A veiculação do Curso de Enfermeiras na Revista Brazil-Medico e Fon-Fon}

No periódico denominado Revista Brazil-Medico, órgão de interesse científico e prático dos profissionais da classe médica brasileira, em colunas franqueadas aos interessados a assumirem a assinatura e responsabilidade das opiniões emitidas (Revista Brazil-Medico, 1918).

O lançamento da revista ocorreu em 15 de janeiro de 1887 destinado ao grupo médico, 
tendo como fundador o médico Antônio Augusto Azevedo Sodré, conhecido como Azevedo Sodré. O periódico era composto por três categorias de colaboradores: professores, médicos e estudantes de medicina. Este veiculava semanalmente dados demográficos, crônicas, noticias médicas, anúncios diversos, casos clínicos e correspondências expedidas e recebidas (Revista Brazil-Medico, 1916).

Dentre as notícias médicas na revista chamou atenção o conteúdo do Curso de Enfermeiras sob o título "Assistência Particular Nossa Senhora da Gloria” veiculado em 10 de janeiro de 1920.

O conteúdo da notícia com dezesseis linhas noticiava que, a referida Instituição teria publicado no Diário Oficial em 7 de janeiro de 1920, o resumo do Estatuto, tendo por objetivo prestar socorro medico, dentários, de parteira e toda a espécie de assistência aos necessitados, serviços estes Ella manterá em sua sêde ou a domicilio, crear hospitalizações, recolhimentos de protecção à infância desprotegida e outros estabelecimentos destinados a amapar os necessitados, assim, como os seus sócios e annexo aos serviços hospitalares creará um curso de enfermeiras, ampliando e creando tantos estabelecimentos e departamentos quantos lhe permitam os recursos (Revista Brazil-Medico, 1920, 26).

No registro noticioso, após o excerto acima, algumas linhas se seguiam no sentido de entendimento de se tratar da justificativa do Curso de Enfermeiras da Instituição, com as seguintes palavras:

Merece especial reparo o projecto do curso de enfermeiras, pois a falta dessas profissionais, competentes, constituem inegavelmente a maior difficuldade com que lutam os directores dos nossos hos- pitaes e casas de saúde (Revista Brazil-Medico, 1920, 26).

A justificativa, assim entendida, corrobora no contexto aqui apresentado de forma panorâmica da época, mediante as propostas de avanço das construções de hospitais no Distrito Federal e a existência de Escolas e Cursos destinados a formação de Enfermeiras, que se faziam necessárias.

Dentre as revistas da imprensa ilustrada que circulavam no Distrito Federal, delimitou-se a Revista Fon-Fon. Esta revista brasileira surgiu no Rio de Janeiro, em 1907. Seu nome era uma onomatopéia do barulho produzido pela buzina dos automóveis "fon-fon". Um de seus idealizadores foi Gonzaga Duque - escritor e crítico de arte.

Nesse sentido, o períodico ou também conhecido como "seminário alegre" tratava de assuntos políticos, críticos, esfuziante, telegrafia, em especial, dos costumes e notícias do cotidiano publicadas até agosto de 1958 (Mauad-Andrade, 1991).

O objetivo da Revista Fon-Fon foi divulgado em 15 de abril de 1907, como:

Fazer rir, alegrar a tua boa alma... com o comentário leve das coisas da atualidade... para os graves problema sua vida, para a mascarada política, para a sisudez conselheiral das finanças e da intricada complicação dos principios sociais, cá temos a resposta propria: aperta-se a sirene...fon-fon! (Revista Fon-Fon, 1907 apudd Maudade-Andrade, 1991, 301).

Ademais, a Revista Fon-Fon também possuia conteúdo panorâmico, no sentido de realizar um contraponto a diversão que proporcionava o periódico, lembrando que por traz das piadas existiam críticas as políticas governamentais como linha editorial da revista. 
Ana Maria Maudad-Andrade (1991) ao analisar algumas imagens veiculadas na imprensa ilustrada, dentre elas da Revista Fon-Fon afirma que, as fotos publicadas eram predominantemente posadas, bem como eram compostas em forma de mosaico dos eventos politicos, esportivos, sociais e artísticos da cidade, juntamente com a vida cotidiana da elite carioca, com destaque para flanerie - palavra de origem francesa, que traduzida significa perambular ou zanzar-, nos espaços reformados pela capital, caracterizando a grande maioria das imagens publicadas.

Essa imprensa ilustrada em meio às imagens veiculadas dos eventos sociais apresentou aos leitores a fotorreportagem, sem título, mas acompanhada de legenda um fac-símile com as alunas e a professora do Curso de Enfermeiras da Assistência Particular Nossa Senhora da Gloria, a qual foi aplicada a matriz de análise.

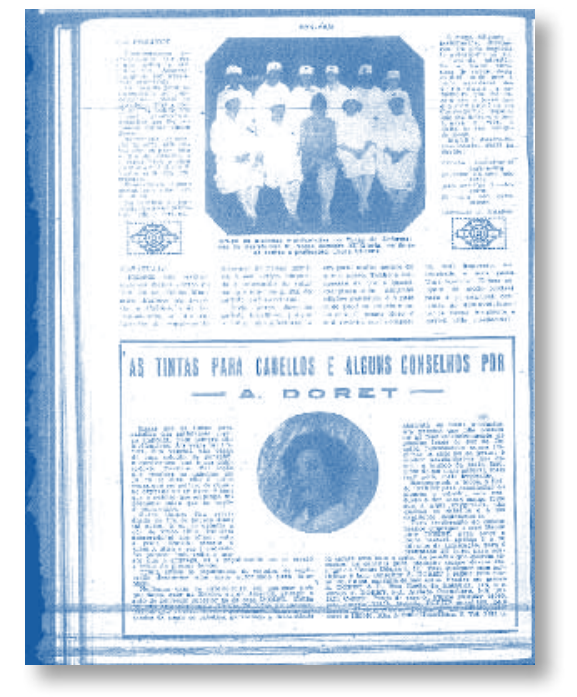

Fac-símiles n. 1 - Página da Revista Fon-Fon $(1928,63)$ com a imagem ao alto das Alunas do Curso de Enfermeiras da Assistência Nossa Senhora da Gloria

A imagem das alunas com a professora do Curso em apreço se encontra em meio a duas colunas de um texto intitulado "Um Romance". Este se referia ao romance de uma moça com um rapaz, que após anos de afastamento geográfico se reencontrou em um hospital, quando ele adoecido necessitou de cuidados, tendo como Enfermeira sua amada do passado marcado pelo diálogo final do texto, com as palavras a seguir de autoria de Leopoldo D. Amaral.

- Venho encontrar-te enfermeira

- Enfermo, ao meu lado estás.

- Mas contigo a cabeceira. Eu, alta não quero mais.

(Amaral, 1928, 63)

O texto e a imagem deixam transparecer carecerem de nexus, à primeira vista, por se tratar de um texto romântico até mesmo, possivelmente, deslocado. Mas após uma leitura mais atenta pode-se inferir que, o conteúdo escrito e imagético teve certa intencionalidade do editorialista, no sentido de tentar mostrar aos leitores, principalmente às mulheres, uma versão romanceada para se abraçar a profissão de Enfermeira.

\section{Aplicação da Matriz de Análise no fac-símile}

Conforme descrito no método do estudo se apresentará a sistematização da aplicação da matriz de análise em imagem delimitada do Curso de Enfermeiras da Assistência Particular de Nossa Senhora da Gloria.

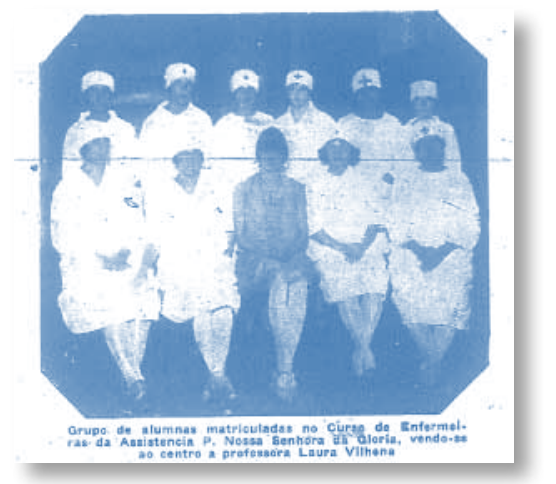

Fac-símiles n. 2 - Alunas do Curso de Enfermeiras da Assistência Nossa Senhora da Gloria (Revista Fon-Fon, 1928) 


\section{Dados de Identificação}

- Local do acervo: Biblioteca Nacional

- Nome da revista ilustrada: Revista Fon-Fon

- Ano de publicação: 1928

- Número do exemplar: 38

- Página que se encontra a imagem fotográfica: 63

- Data da publicação do exemplar da revista: 22/09/1928

- Título ou manchete que acompanha a fotografia: não tem

\section{Dados para o Plano de Expressão}

- Crédito da imagem fotográfica: autoria desconhecida

- Relação texto Imagem: fotorreportagem

- Legenda: Grupos de alunnas matriculadas no Curso de Enfermeiras da Assistência P. Nossa Senhora da Gloria, vendo-se ao centro a professora Laura Vilhena.

- Resumo do texto: não se aplica

- Tipo de foto: posada

- Formato: irregular

- Plano: detalhe

- Sentido: horizontal

- Localização da imagem na página: entre as zonas 1 e 3

\section{Dados para o Plano de Conteúdo}

- Local retratado: natural e interno

- Pessoas retratadas: grupo feminino de 11 mulheres

- Tema da imagem retratada: matriculadas no curso

- Atributos:

- Pessoais:

- Trajes femininos:

- Roupa social, com chapéu e meias e sapatos referentes à mulher no centro ótico da imagem em primeiro plano

- Uniforme - vestido na cor clara de golas no formato "v" e arredon- dado; mangas cumpridas e de três quarto, ostentam gorros com o símbolo da cruz na cor escura e sapatos na cor escura.

- Paisagem: os atributos de paisagem são pouco visíveis na imagem em virtude escurecimento ao fundo, mas se acredita tratar-se de ambiente interno e natural

\section{Dados Complementares obtidos de outras imagens fotográficas}

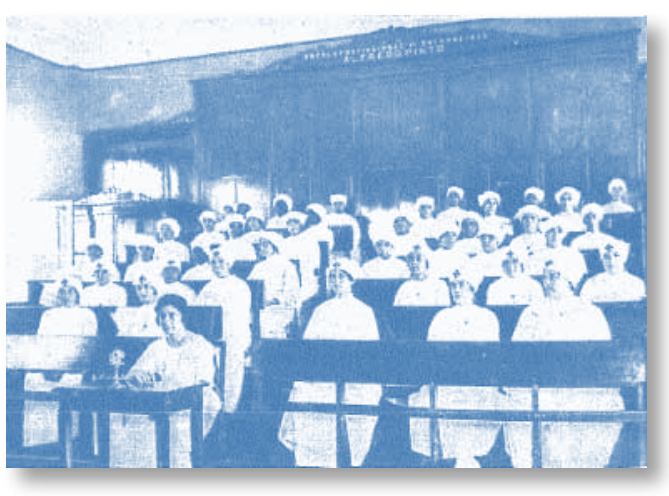

Fac-símile n.3: Turma de Enfermeiras da Escola Profissional de Enfermeiras Alfredo Pinto (Revista da Semana, 1921, p.23).

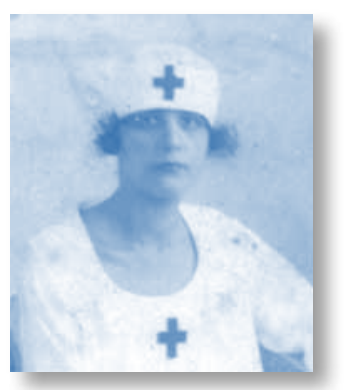

Fotografia n.1 - Enfermeira Profissional da Escola Prática da Cruz Vermelha Brasileira - Órgão Central (Acervo da Cruz Vermelha Brasileira, 192[0?])

- Origem da informação: Fac-símile n.3 Revista da Semana, 18/6/1921, p.23 - e Fotografia n.1 - Acervo da Cruz Vermelha Brasileira - Órgão Central, sem data de registro. 
- Informação complementar: referente ao gorro, caso não tivesse a imagem à legenda, poderia a mesma ser confundida com alunas ou enfermeiras da Escola Profissional de Enfermeiros e Enfermeiras ou, então, do Curso de Enfermeiras Profissionais da Escola Prática da Cruz Vermelha Brasileira - Órgão Central, que também ostentavam um gorro semelhante.

Outro elemento simbólico, que se aproxima das Escolas acima citadas é o símbolo da cruz. Este símbolo se distingue entre as duas Escolas pela cor, apesar das imagens já pesquisadas serem na escala de cinza, documentos escritos permitiram assertivas de se tratarem das oriundas da Escola Profissional de Enfermeiros e Enfermeiras na cor azul e da Escola Prática de Enfermeiras da Cruz Vermelha, na cor vermelha regulamentada pela Instituição.

\section{Síntese Interpretativa}

Depreende-se disso, que à época investir na formação de profissionais de enfermagem era de fato contribuir para o desenvolvimento do país, se podendo arriscar a assertiva que se estaria modernizando o Brasil, como o contexto histórico social-político expressava.

Além disso, em especial as imagens, podem ser reveladoras ao serem perscrutadas seja melhor contextualizar a história, bem como para revelar aspectos que outros estudos, ainda, não desvelaram.

No caso do estudo, a imagem foi reveladora, pois o texto escrito e publicado na Revista Brazil-Medico em 1920, sinalizou a intenção de um Curso de Enfermeiras e a imagem em 1928 materializou-a, mesmo carecendo saber se elas de fato se formaram.

Ao final se às aspirantes a Enfermeiras de fato se formaram carece de dados para a assertiva. Por outro lado, a evidencia apresentada no estudo da iniciativa do Curso de Enfermei- ras da Assistência Nossa Senhora da Gloria se trona relevante para entender como se deu o processo profissionalização da Enfermagem no Brasil, delimitado no Rio de Janeiro, bem como serve de alerta aos interessados na pesquisa histórica da Enfermagem sobre certas assertivas que muitas vezes precisam ser relativizadas, pois o que move a pesquisa é o desvelar de novos dados/documentos e suas interpretações.

\section{REFERENCIAS BIBLIOGRAFICAS}

- Amaral, L. D.Um Romance. (1928). Revista Fon-Fon. 22(38). Rio de Janeiro (Brasil):63.

- Ciavatta, M. (2002). O mundo do trabalho em imagens - a fotografia como fonte histórica (Rio de Janeiro, 19001930). DP\&A e FAPERJ. Rio de Janeiro (Brasil).

- Fonseca, EFR. e Porto, F. Fac-símile na pesquisa em História da Enfermagem Obstétrica: inauguração da capela da Pro-Matre (1923). Revista de Pesquisa: Cuidado é Fundamental Online. 2(4). Rio de Janeiro (Brasil). Disponível em: http://www.seer.unirio.br/index.php/cuidadofundamental/article/view/1315/pdf_236. Capturado em 20 de dezembro de 2010.

- Leite, MM. (1993). Retratos de Família: Leitura da Fotografia Histórica. Universidade de São Paulo. São Paulo (Brasil).

- Mauad-Andrade, AMS. (1991). Sob o signo da imagem. A produção fotográfica e o controle dos códigos de representação social da classe dominante do Rio de Janeiro da primeira metade do século XX. Volume I. [Tese de Doutorado]. Rio de Janeiro (Brasil). Universidade Federal Fluminense. Curso de História.

- Moreira, A. (1995). Desmistificando a origem da enfermagem brasileira. História da Enfermagem - versões e interpretações. Revinter. Rio de Janeiro (Brasil):43-160.

- Mott, MA;Tsunechiro, A. (2002). Os Cursos de Enfermagem da Cruz Vermelha Brasileira e o início da enfermagem profissional no Brasil. 55(5). Revista Brasileira de Enfermagem. Rio de Janeiro (Brasil): 592-599.

- Mott ML, Oguisso, T. (2002).Discutindo os primórdios do ensino de enfermagem no Brasil: o Curso de 
Enfermeiras da Policlínica de Botafogo (1917-1920). 22(1). Revista Paulista de Enfermagem. São Paulo (Brasil);82-92.

- Porto, F, Santos, TCF. (2008). A enfermeira na mira do clcik fotográfico. História da Enfermagem Brasileira ritos, lutas e emblemas. Editora Águia Dourado. Rio de Janeiro (Brasil): 25-188.

- Porto,F e Amorim, W. (2010). Escolas e Cursos da Enfermagem na História da Profissão no Brasil (890-1922). Revista Cultura de los Cuidados. 14(27). Alicante (Espanha):40-45

- Pietroforte, A. (2002). V. Semiótica Visual - os percursos do olhar. Contexto. São Paulo (Brasil).

Prefeitura do Distrito Federal. (1922). Assistência Pública e Provada no Rio de Janeiro; história e estatística. Tipografia do Anuário do Brasil. Rio de Janeiro (Brasil).

- Rangel, RF. (2010). A Laicização da Assistência Social na Primeira República. XIV Encontro Regional da ANPUH-RIO Memória e Patrimônio. Associação Nacional de História. UNIRIO. Rio de Janeiro (Brasil).

- Revista Brazil-Medico. (1918). Brazil-Medico. 32(1). Rio de Janeiro (Brasil):1.

- Revista Brazil-Medico. (1916). Professor Azevedo Sodré. 30(20). Rio de Janeiro (Brasil): 153-154.

- Revista Brazil-Medico. (1920). Assistência Nossa Senhora da Gloria. 34(2). Rio de Janeiro (Brasil): 26.

- Revista da Semana. A Escola Profissional de Enfermeiras na Colonia de Alienadas. 22(25). Rio de Janeiro (Brasil):23.

- Sauthier, J e Barreira, IA. (1999). As Enfermeiras norte-americanas e o snsino da enfermagem na capital do Brasil (1921-1931). UFRJ. Rio de Janeiro (Brasil).

- Santaella, L e Noth W. (1999). Imagem- Cognição. Semiótica, Mídia. Iluminuras. São Paulo. (Brasil).

- Sanglard, G. (2008). A Primeira República e a Constituição de uma Rede Hospitalar no Distrito. História da Saúde no Rio de Janeiro. Porto, A; Sanglard, G; Fonseca, MRF; Costa, RGR (org.). FIOCRUZ. Rio de Janeiro (Brasil): 61-88.

- Silva, RS. (1985). Diagramação - o Planejamento visual gráfico na comunicação impressa. Summus. São Paulo (Brasil).
- Santos, TCF, Barreira, IA. (2002). O Poder simbólico da Enfermagem Norte-americana no ensino da Enfermagem na capital do Brasil (1928-1938). UFRJ. Rio de Janeiro (Brasil).

- Santos, TCF. A Câmera Discreta e o Olhar Indiscreto: A Persistência da Liderança Norte-Americana no Ensino da Enfermagem na Capital do Brasil (1928-1938). (1998).[Tese de Doutorado]. Rio de Janeiro (Brasil). Universidade do Rio de Janeiro. Escola de Enfermagem Anna Nery.

- Viscardini, C.M. R.(2009). Estratégias populares de sobrevivência: o mutualismo no Rio de Janeiro republicano. Revista Brasileira de História. 29 (58). São Paulo (Brasil). Disponível em http://www.scielo.br/scielo. php?pid=S0102-01882009000200003\&script $=$ sci_art text. Capturado em 20 de dezembro de 2010. 